\title{
Optimal design selection and analysis of single sided linear induction motor
}

\author{
Sijitha Issac $^{1^{*}}$, S. Poorani2 ${ }^{2}$ \\ ${ }^{1}$ Department of Electrical \& Electronics, Karpagam Academy of Higher Education, Coimbatore, India. \\ ${ }^{2}$ Professor, Department Electrical \&Electronics Karpagam Academy of Higher Education, Coimbatore, India. \\ *Corresponding author E-mail: sijithaissac@gmail.com
}

\begin{abstract}
This paper investigates the design and implementation of single-sided linear induction motor towards determining the end effect intensity, reduces the primary weight of the system and improves the efficiency by multi-objective optimisation approach. This optimisation technique is a combination of genetic with cuckoo search (GCS) algorithm is introduced to improvise the efficiency and power factor, as well as to minimize the end effect intensity, simultaneously. The performance of the designed novel approach will be validated based on the measure of different parameters such as Efficiency, Power factor, Maximum thrust slip, Aluminum thickness, Primary width/pole pitch, Primary current density and the braking force due to the end effect. Finally, to validate the optimisation results, 3D finite element method is employed and compared the results with the existing technique like GA, PSO, and Cuckoo search.
\end{abstract}

Keywords: Optimization technique, induction motor drive, power factor, single-sided linear induction motor, efficiency.

\section{Introduction}

Induction Motors (IMs) are extensively used in many applications and they account for nearly $60 \%$ of total electricity consumption in industries (which includes industrial sectors of air compressors, pumps, cranes, electric home appliances, wind generation systems, fans, textile mills, blowers and in transportation systems) due to the dependency in conversion of electrical to mechanical energy [1]-[3]. Moreover, the maintenance of IMs is easy due to its simple structure, low cost, high efficiency and reliability [4][7]. In the past, DC motor drives were employed with speed controls due to their simple design in regulating flux as well as torque. However, the maintenance of DC motors is difficult as they corrode [3], [8], [9]. Then, AC motors came into existence in place of DC motors followed by semiconductor devices like metal oxide semiconductor field-effect transistor, insulated gate bipolar transistor was developed and simultaneously improved [8]-[10]. The AC motors are designed using the microcontroller, Digital Signal Processor (DSP), and Field Programmable Gate Array (FPGA) in order to solve the fundamental and challenging problems [3], [9], [11]. Moreover, in IMs, the controlling of flux, speed and torque are difficult because of its sophisticated design along with its non-linear model [9], [10], [12], [13]. Linear motors are considered to be electrical machines with unique characteristics, in which the electrical energy is directly converted into mechanical energy with linear movement without the use of rotary for linear conversion.

There are several kinds of linear motors which include permanent magnet motors, DC motors, synchronous motors, stepping motors and among which Linear Induction Motor (LIM) is the one considered to be promising because of its high-speed operation, simple construction, absence of gear between motor and other motion devices, high-starting thrust force, reduced mechanical losses, silent operation, small motion devices, low friction, no backlash, suitability for low as well as high speed applications and easy maintenance [14].

Therefore, for many applications LIMs are used widely with satisfied performance like in transportation, actuators, in pumping liquid metals, robot base movers, automation, elevators, conveyor systems, material handling and in elevators [15], [16] because of its low-cost of construction lines as well as stations which use small cross-section, improved steepness gradient and sharpness of electromagnetic field curves. Nevertheless, LIMs face limitations in end effect and presence of large air gap, which leads to low efficiency and power factor.

Hence, many researchers have concentrated to reduce the causes due to end effect and further to enhance the LIM's efficiency [17]. Few of them recommended for optimisation using the multiobjective genetic algorithm in order to increase the power factor of the motor and efficiency. Subsequently, single-sided linear induction motors (SLIM) have also been developed, and more considerable efforts have been put on the ECM (equivalent circuit model). Furthermore to attain better performance, i.e. high efficiency and power factor, [18]-[22] have made many research works to design the SLIM. Unfortunately, these works either fall short to consider the coupling relationship among all structure parameters fully or fail in aligning proper constraints to meet the standard working conditions[23].

Also, from the review of the existing literature studies, it can be recognised that only some of the studies focused towards the optimisation of SLIM.

Optimization techniques namely, GA[23], [24],PSO[25],cuckoo search algorithm[26], backtracking search algorithm[27], etc., are being used in many studies in order to enhance the performance of IM drives, in particular, its control systems[28]-[30]. In [31], GA was applied to improve the fuzzy-phase plane controller for speed tracking/ ideal position control in IM. Similarly, for optimum torque control and loss minimisation operation in IMs, GA-PSO algorithm was used to enhance the indirect vector control[23], [32], [33] likewise, for model-parameter identification technique, PSO was applied in permanent-magnet synchronous motors. 
Correspondingly, for controlling IM drives predictive torque control technique which uses multi-objective fuzzy decision making was used and provided fast dynamics and high performance.

In [34], in order to improve the performance of fuzzy logic speed controller[12], backtracking search algorithm (BSA) was utilised in IMs[27]. Nevertheless, these optimisation techniques mostly had limitations on local minima, global minimum, optima trapping, trial-and-error procedure; further also have drawbacks in expanding the algorithms and reducing the computational time to attain optimal performances through optimisation. Hence, to overcome the above optimisation problems as well as to control the speed response in IMs based on transient response and damping capability under various speed and load conditions, a novel technique is required[13]. To meet the above requirements, this study focuses on different control and optimisation techniques to achieve high efficiency and power factor, as well as to minimize the end effect intensity.

\section{Methodology}

In this section, the design of a single-sided linear induction motor using a hybrid approach of the combination of multi-objective cuckoo search optimization algorithm with the genetic algorithm is presented.

The designed motor is simulated using MATLAB software and investigates the effect of the design parameters based on the machine performance.

Then validated the model parameters and optimised results using finite element method.

By using this approach, the power factor and efficiency can be improved. The motor design independently controls the forces produced by the SLIM.

The model is based on an equivalent circuit of the SLIM, and it describes how the forces behave as a function of the primary current. Based on this behaviour, the next model will be used for the decoupling of the forces and control of the SLIM. The primary objective of this research is:

- To define optimum design parameters, a multi-objective optimisation problem which includes efficiency, power factor, end effect intensity and the braking force due to the end effect.

- To measure the voltage, current, and the phase shift between them under free acceleration, and investigate the effect on the propulsion force under locked primary condition.

- To compare the performance of proposed optimised results with the existing approaches (genetic, cuckoo search algorithm, PSO).

- To validate the obtained solution using a 3-D timestepping finite-element method.

- To enhance the efficiency as well as to reduce the primary weight of the system

\section{A. Equivalent circuit model of LIM}

Figure 1 shows the architecture of the SLIM. It contains a threephase primary, and an aluminum laid sheet on the secondary back iron [35]. The per-phase equivalent circuit model of SLIM is shown in Fig. 2.

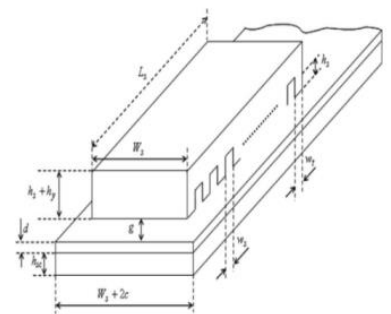

Fig.1. Architecture of a single-sided LIM[36]

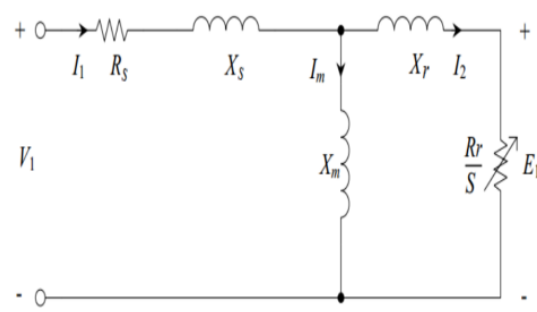

Fig.2. Equivalent circuit of a LIM[36]

Per-phase stator resistance

$R_{S}=\frac{\rho_{w} I_{w}}{A_{w t}}$

Per-phase stator-slot leakage reactance

$X_{s}=\frac{2 \mu_{0}\left[\left(\lambda_{s}\left(1+\frac{3}{p}\right)+\lambda_{d}\right) \frac{W_{s}}{q}+\lambda_{e} I_{c e}\right] N^{2}}{P}$

Slot, differential and end connection permeance are

$\lambda_{s}=\frac{h_{s}\left(1+3 k_{p}\right)}{12 w_{s}}$

$\lambda_{d}=\frac{5\left(\frac{g_{e}}{w_{s}}\right)}{5+4\left(\frac{g_{0}}{w_{s}}\right)}$

$\lambda_{e}=0.3\left(3 k_{p}-1\right)$

Magnetizing Reactance per phase

$X_{m}=\frac{24 \mu_{0} \pi f w_{s e} K_{W} N_{l}^{2} \tau}{\pi^{2} p g_{e}}$

Per-phase rotor resistance

$R_{r}=\frac{X_{m}}{G}$

$G=\frac{2 \mu_{0} f_{1} \tau^{2}}{\pi\left(\frac{\rho_{r}}{d}\right) g_{e}}$

\section{Goodness factor}

Where, $\rho w$ - volume resistivity of the copper wire used in the stator winding;

lw - copper wire length per phase;

$\rho r$ - volume resistivity of the rotor conductor outer layer;

Awt - cross-sectional area of the wire:

ge - equivalent air gap;

wse - equivalent stator width;

$\mathrm{kp}$ - pitch factor; 
fl - primary frequency;

$\mathrm{kw}$-winding factor.

To maintain air gap flux density below $0.5 \mathrm{~T}$, then the iron losses are negligible, and the thrust, the efficiency and the power factor will be given by

$$
\begin{aligned}
& F_{S}=\frac{m I_{1}^{2} R_{r}}{\left[\frac{1}{(s G)^{2}}+1\right] s V_{S}} \\
& \eta=\frac{F_{S} 2 \tau f_{1}(1-s)}{F_{S} 2 \tau f_{1}+3 I^{2} R_{1}} \\
& \cos \varphi=\frac{F_{S} 2 \tau f_{1}+3 I^{2} R_{1}}{3 V I}
\end{aligned}
$$

The effect of different parameters on efficiency and power factor and hence it is necessary to employ an optimisation method to achieve required specifications.

Table 1 describes design variables of optimisation problems for SLIM.

Most of the standard LIM dimensions and variables are opted as design variables whose values are found by optimisation procedure by GSA technique.

In this study, the considered draft variables are the given in the table 1 .

Table I. Design variable constraints

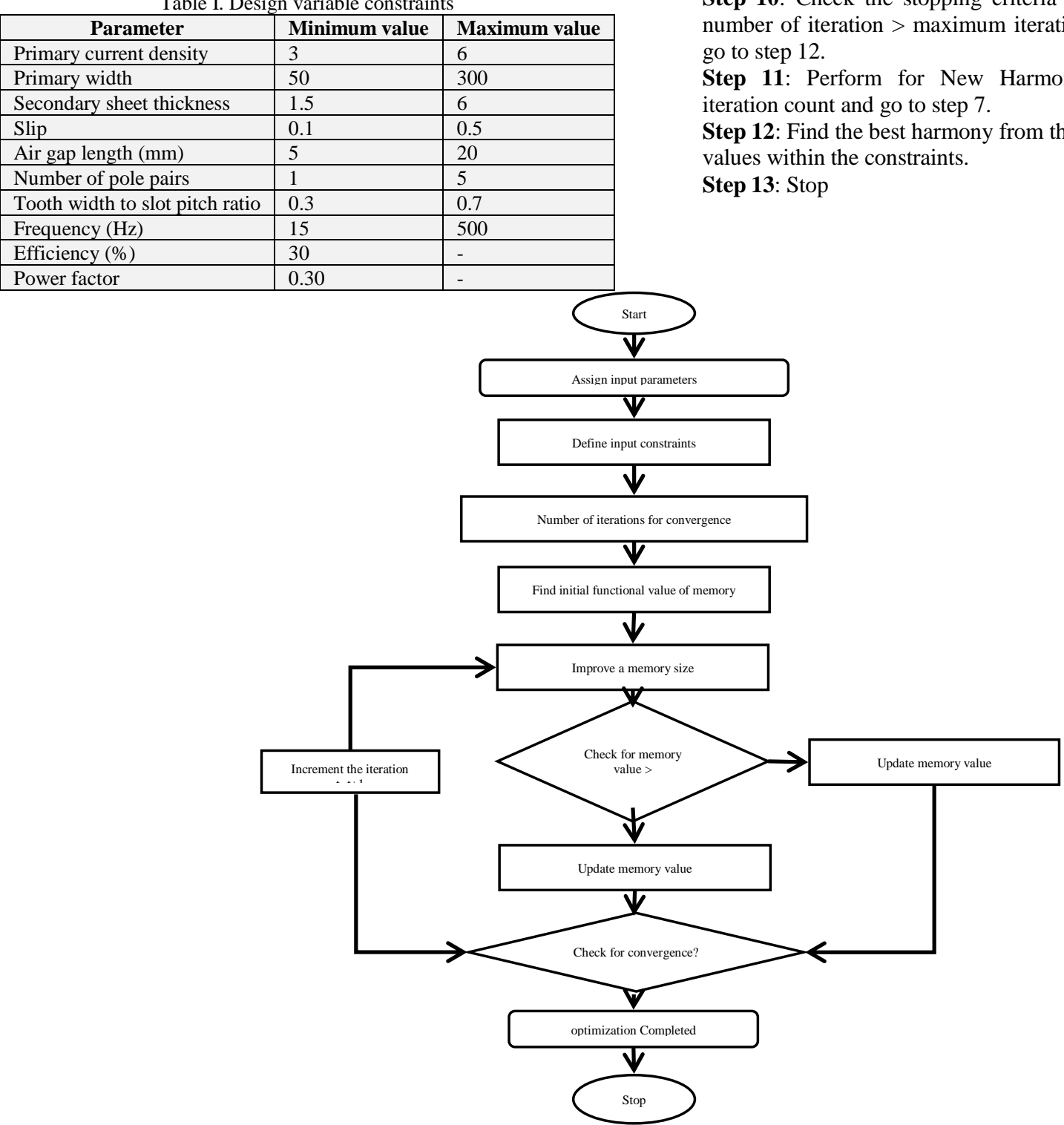

\section{B. Identification of LIM parameters using GCS}

In order to improve efficiency and power factor of SLIM, the effective design parameters should be known. In this section design parameters are chosen as Efficiency, Power factor, Maximum thrust slip, Aluminum thickness, Primary width/pole pitch, Primary current density and the braking force due to the end effect. The design variables and constraints are as listed in table 1.

Genetic with cuckoo Search Algorithm (GCS) is an optimization algorithm is an advanced process control and optimization for industrial scale systems. Steps involved in the process of GCS are as follows:

Step 1:Assign the number of parameters to be identified for a SLIM

Step 2: Initialize the GCS parameters such as memory, memory considering rate (MCR), pitch adjusting rate (PAR), bandwidth $(\mathrm{BW})$ and a number of iterations for convergence.

Step 3: Define the multi-objective function

Step 4:Definethe range of values for the function variables.

Step 5:Obtain the functional value of initial Harmony memory.

Step 6: Set iteration counter $\mathrm{t}=0$

Step 7:Increment the iteration counter $t=t+1$.

Step 8:Starting of cuckoo Search, if generated random value $>$ MCR. Then select the value of parameter randomly

Step 9: Update the memory of objective function and replace the worst solution with a new better solution.

Step 10: Check the stopping criteria and convergence, i.e., number of iteration > maximum iteration, if it is Satisfied to go to step 12 . Step 12: Find the best harmony from the HM. i.e., the optimal values within the constraints.

Step 13: Stop 
Fig. 3. Flowchart

\section{Finite element analysis for LIM using GCS}

The design optimisations were carried out based on the analytical model of the machine and presented in Section III. However, the model is obtained by simplifications such as considering saturation, the nonlinearity of materials, etc. Thus, in this section 3-D time stepping FEM are employed to evaluate the new equivalent circuit LIM model. The Commercial computer software (CCS) is one of the most important and efficient software for 3-D FEM analysis and also to obtain numerical and graphical results. The incomplete Cholesky conjugate gradient (ICCG) method used to solve the finite-element equations.

Table II: Optimized Motors Specification

\begin{tabular}{|l|l|l|l|l|}
\hline \multicolumn{1}{|c|}{ Parameters } & Original & $\begin{array}{c}\text { Optimal } \\
\mathbf{1}\end{array}$ & Optimal & $\begin{array}{c}\text { Optimal } \\
\mathbf{3}\end{array}$ \\
\hline Stack height(mm) & 266 & 266 & 266 & 266 \\
\hline Primary length(mm) & 1950 & 2341 & 2333 & 2333 \\
\hline Primary depth(mm) & 98.6 & 119.6 & 114.6 & 114.6 \\
\hline Slot width (mm) & 15.87 & 19.3 & 19 & 18.8 \\
\hline Tooth Width (mm) & 8.4 & 10.2 & 10.4 & 10.6 \\
\hline Slot depth(mm) & 58 & 83.6 & 79.1 & 74.2 \\
\hline Pole pitch (mm) & 291.2 & 265.5 & 264.6 & 264.6 \\
\hline No .of slots & 80 & 79 & 79 & 79 \\
\hline $\begin{array}{l}\text { Mechanical } \\
\text { clearance(mm) }\end{array}$ & 12 & 12 & 12 & 12 \\
\hline No.of slots/pole/phase & 4 & 3 & 3 & 3 \\
\hline Short pitch factor & $8 / 12$ & $7 / 9$ & $7 / 9$ & $7 / 9$ \\
\hline Conductor area(mm^2) & 67.19 & 117.78 & 109.71 & 101.83 \\
\hline Number of poles & 6 & 8 & 8 & 8 \\
\hline $\begin{array}{l}\text { Secondary sheet } \\
\text { thickness(mm) }\end{array}$ & 4 & 4 & 4 & 4 \\
\hline $\begin{array}{l}\text { Secondary sheet width } \\
\text { (mm) }\end{array}$ & 354 & 354 & 354 & 354 \\
\hline $\begin{array}{l}\text { Back-iron } \\
\text { thickness(mm) }\end{array}$ & 25 & 25 & 25 & 25 \\
\hline Base velocity(Km) & 40 & 40 & 40 & 40 \\
\hline Slip frequency & 6.0 & 6.0 & 5.8 & 5.7 \\
\hline Primary weight & 628 & 662 & 632 & 628 \\
\hline Thrust (kN) & 18.60 & 18.60 & 18.60 & 18.60 \\
\hline Efficiency & 0.6555 & 0.7049 & 0.7022 & 0.7069 \\
\hline Powerfactor & 0.5055 & 0.4718 & 0.4657 & 0.4778 \\
\hline & & & & \\
\hline
\end{tabular}

In FEM, using time-stepping analysis the change in levitated and position that is based on the current location is called relative moment is measured. The force is created by a linearly moving magnetic field acting on conductors in the fields are then calculated using local virtual work method. The optimum designed SLIM is numerically simulated, and the accuracy of the calculated specifications is validated by 3-D finite-element method (FEM) results. From the above table, it can be interpreted that the proposed model has produced optimal results when compared with the original values.

\section{Experimental results}

The novel optimisation GCS has been applied to meet required efficiency, power factor, reduces the primary weight of the system, improves the efficiency and minimise the end effect intensity in the design of single-sided Linear Induction Motor.

\section{A. Performance measurement}

The interactive user design of the SLIM is examined briefly and the results obtained are tabulated. The performance curves are drawn and analysed for differently rated slip and thrust values. The effect of the different parameters of SLIM like number of poles, air-gap, the thickness of aluminum sheet is investigated.

The calculation of output power and input power is done in order to determine the efficiency of the proposed model At a specific synchronous velocity $\mathrm{Vs}$, the rated rotor velocity $\mathrm{Vr}$ is computed at distinct slips from 0 to 1.Further,the performance characteristics of the considered parameters like number of poles, thrust, end effect, linear speed, time, slip frequency, gain and efficiency are discussed below.

The evaluation of the performance of the proposed algorithm is evaluated based on the following factors:

- $\quad$ Effect of number of poles on the thrust of LIM (Velocity vs Force) When there is an increase in the number of poles, then there is a reduction in the end effects. Since the end-effect loss is divided by many numbers of poles, which results in better performance. Therefore, a machine with many numbers of poles is advantageous. For a given frequency and synchronous speed, the LIM can be very long unless the number of poles is considered. The thrust also increases, when the number of poles is increased. We can interpret from the experimental results, that efficiency decreases when the number of poles is increased. Hence, trade-off exists between efficiency and thrust with an increase in the number of poles. Similarly, there is a restraint in the length of the motor, which increases with increase in number of poles when supply frequency and synchronous velocity are considered to be constant.

- Effect of number of poles on the efficiency of LIM (Efficiency vs Velocity) When the number of pole increases, the efficiency decreases and the power factor increases. Effects of number of poles and the efficiency are illustrated. It is clear that larger current densities increase the power factor and reduce the effectiveness of SLIMs.

Table III: Experimental Results

\begin{tabular}{|l|l|l|}
\hline \multicolumn{1}{|c|}{ Parameter } & Results & FEM \\
\hline Efficiency (\%) & 69 & 68.03 \\
\hline Power factor & 0.6631 & 0.6974 \\
\hline Output thrust (N) & 974.32 & 994.9 \\
\hline
\end{tabular}

The efficiency is $47.36 \%$, as higher as when compared to other existing algorithms. When the target thrust is $1000 \mathrm{~N}$, and the actual thrust developed by the SLIM is $994.9 \mathrm{~N}$ at an efficiency of $46.03 \%$ compared to the design from table 3. This has a better ratio of slot width to tooth width when compared to the previous systems. Hence, the final thrust obtained from these experiments conducted with these designs is much closer to the target thrust even with better efficiency.

Table IV: Optimization Results and Conventional Motor Parameters

\begin{tabular}{|l|l|l|l|l|l|l|}
\hline Parameter & $\begin{array}{c}\text { Conventio } \\
\text { nal } \\
\text { design[37] }\end{array}$ & $\begin{array}{c}\text { GA[3 } \\
5]\end{array}$ & $\begin{array}{c}\text { PSO[2 } \\
\text { 2] }\end{array}$ & $\begin{array}{c}\text { ICA[3 } \\
7]\end{array}$ & $\begin{array}{c}\text { Cuckoo } \\
\text { search[ } \\
\text { 26] }\end{array}$ & $\begin{array}{l}\text { Propos } \\
\text { ed }\end{array}$ \\
\hline $\begin{array}{l}\text { Efficiency } \\
(\%)\end{array}$ & 36 & 39.30 & 54.68 & 43.45 & 49.01 & 69 \\
\hline $\begin{array}{l}\text { Maximum } \\
\text { thrust slip }\end{array}$ & 0.5 & 0.5 & 0.3 & 0.5 & 0.5 & 0.6729 \\
\hline Power factor & 0.32 & 0.3 & 0.58 & 0.6463 & 0.5729 & 0.8 \\
\hline $\begin{array}{l}\text { Primary } \\
\text { current } \\
\text { density(Amm } \\
-2 \text { ) }\end{array}$ & 4 & 3 & 6.5 & 5 & 3 & 7.5 \\
\hline $\begin{array}{l}\text { Primary } \\
\text { width/pole } \\
\text { pitch(mm) }\end{array}$ & 2 & 2.5 & 4 & 4 & 2 & 6 \\
\hline $\begin{array}{l}\text { Aluminum } \\
\text { thickness(inc } \\
\text { hes) }\end{array}$ & 2 & 1.4 & 4 & 1 & 1 & 5.5 \\
\hline
\end{tabular}


Genetic algorithm has $39.30 \%$ efficiency but power factor is 0.5 less than the required, particle swarm optimisationhas $30 \%$ but power factor is 0.3 less than needed, but GCS gives $69 \%$ and also reached required power factor. From table4the GCS has less number of iteration and better pattern search to reach desired optimum values as compared to GA, PSO and cuckoo search algorithms.

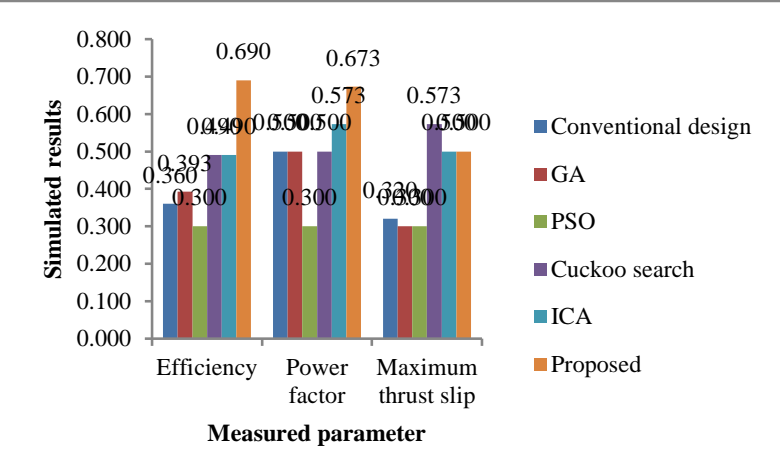

Fig. 4. Comparison of Efficiency,

Power factor and maximum thrust slip The motor dimensions and properties of the genetic algorithm, PSO, cuckoo search algorithm and designed GCS optimisation methods which are mentioned. The above figure 4 shows that the maximum efficiency is achieved for the developed GCS algorithm. Also, the highest of power factor is obtained in GCS far better than separate GA, ICA and cuckoo search system. GCS attained enhanced power factor around 20\% times better than the cuckoo search algorithm. In another aspect, GCS enhanced both power factor and efficiency around 2 and $20 \%$ times respectively which is very significant. It is valuable note to mention that GCS improved both efficiency and power factor in the comparison with traditional state-of-art algorithms and the necessary target parameters is much more optimized.

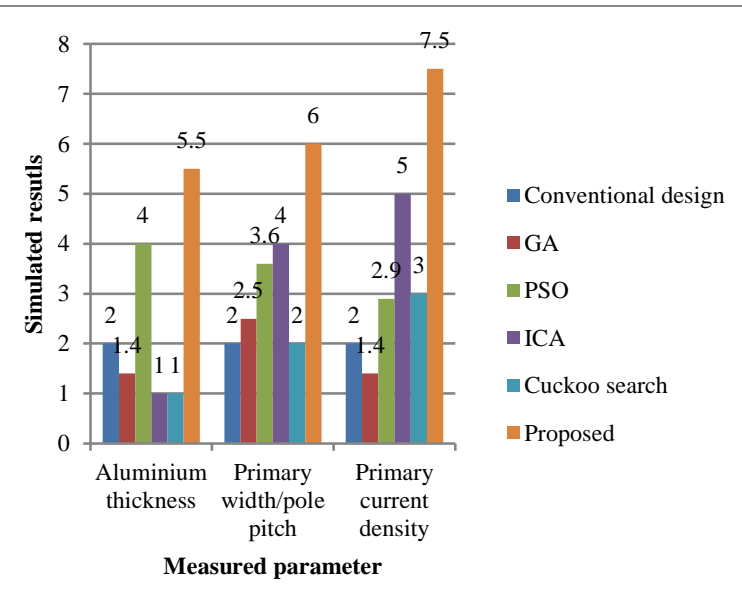

Fig. 5. Comparison of Aluminium thickness, primary width and current denssity

Illustrate the changes in the efficiency with respect the air gap length and the aluminum thickness. Fig. 5 illustrates comparison of the aluminum thickness, primary width/pole pitch and primary current density for the proposed model with the considered state of art algorithms such as GA, PSO, and Cuckoo search algorithm and ICA algorithm. It is clear that a reduction in the air gap length and the aluminum thickness leads to a growth in the power factor magnitude.

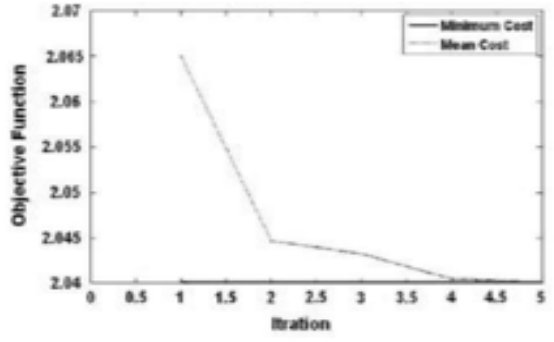

Fig. 6. No.of iteration Vs. obj. function

Figure6 demonstrates the Mean and minimum cost of all imperialists versus iteration in the optimisation problem. Hence from this iteration convergence graph we can conclude that the proposed work has lesser no of iteration than the other conventional approach.

\section{Discussion}

The performance of the SLIM can be governed by efficiency as well as losses. There are many parameters that lead to causes, but most researchers focused on longitudinal end effect in order to improve the performance. The common factor of end effect is magnetic field distribution. The magnetic field distribution can be increased by increasing the air gap between primary and secondary, whereas efficiency depends on goodness factor, power factor,correction factor which are influenced by slot pitch, secondary sheet thickness, air gap and tooth width. Correction factor depends on the property of slot pitch, air gap and backplate thickness. In high-speed operations, end-effect compensation has to be done for balancing the system. Thus, end-effect compensation scheme is applied for accurate orientation of rotating reference frame including the basic flux linkage. For determining the performance of the SLIM, goodness factor can be used which is a metric that depends on the permeability of the core, the conductivity of the conductor, area and length of electric as well as a magnetic circuit, and angular frequency of the motor. There will be rise in the magnetic air-gap when the thickness of the aluminum sheet present in the rotor is increased than the specified value so that the flux linkage decreases the currents formed between the stator and rotor. Therefore, the value of the density of secondary conductor must be maximum. The primary factor in the design of SLIM is the air-gap. Increased air-gap requires larger magnetising current and so leads to lower power factor. While in case of low-speed SLIM, increased goodness factor will result in efficient performance. Therefore, for mechanical feasibility air-gap must be minimum.

\section{Conclusion}

In this paper, multi-objective optimisation methods were used for optimised dimensions of a single-sided linear induction motor to meet required efficiency and power factor simultaneously. It is observed that the usage of the Genetic with cuckoo search algorithm has resulted in an efficiency of $69 \%$ with a power factor of 0.6729 less than the required. The utilization of GCS resulted in an enhanced efficiency and also reached the required power factor. From FEMM analysis, GCS based SLIM flux and eddy current density are less when compared to PSO based LIM. Based on the results, we conclude that design of LIM using GCS optimisation technique takes less converging time, less number of iterations, desired optimum values to achieve the desired efficiency, power factor and high speed. 


\section{References}

[1] Suetake M, Da Silva IN \& Goedtel A, "Embedded DSP-Based Compact Fuzzy System and Its Application for Induction-Motor V/f Speed Control", IEEE Trans. Ind. Electron., Vol.58, No.3, (2011), pp. 750-760.

[2] Marino R, Tomei P \& Verrelli CM, "An adaptive tracking control from current measurements for induction motors with uncertain load torque and rotor resistance", Automatica, Vol.44, No.10, (2008), pp. 2593-2599.

[3] Reza CMFS, Islam MD \& Mekhilef S, "A review of reliable and energy efficient direct torque controlled induction motor drives", Renew. Sustain. Energy Rev., Vol.37, (2014), pp.919-932.

[4] Dos Santos TH, Goedtel A, Da Silva SAO \& Suetake M, "Scalar control of an induction motor using a neural sensorless technique", Electr. Power Syst. Res., Vol.108 (2014), pp.322-330.

[5] Kashif SAR, Saqib MA \& Zia S, "Implementing the inductionmotor drive with four-switch inverter: An application of neural networks", Expert Syst. Appl., Vol.38, No.9, (2011), pp.1113711148

[6] Siddique A, Yadava GS \& Singh B, "A Review of Stator Fault Monitoring Techniques of Induction Motors," IEEE Trans. Energy Convers., Vol.20, No.1, (2005), pp.106-114.

[7] Alsofyani IM \& Idris NRN, "A review on sensorless techniques for sustainable reliablity and efficient variable frequency drives of induction motors", Renew. Sustain. Energy Rev., Vol.24, (2013), pp.111-121.

[8] Sikarwar S \& Barve A, "Discrete PI and PID controller based three phase induction motor drive: a review", Int. J. Electr. Comput. Eng., Vol.2, (2013), pp.97-100.

[9] Demirtas M, "DSP-based sliding mode speed control of induction motor using neuro-genetic structure", Expert Syst. Appl., Vol.36, No.3, (2009), pp.5533-5540.

[10] Rong-Jong W, Jeng-Dao L \& Kuo-Min L, "Robust decoupled control of direct fieldoriented induction motor drive", In Control Conference 5th Asian, (2004), pp.1346-1353.

[11] Zhang D \& Li H, "A Stochastic-Based FPGA Controller for an Induction Motor Drive with Integrated Neural Network Algorithms", IEEE Trans. Ind. Electron., Vol.55, No.2, (2008), pp. 551-561.

[12] Rafa S, Larabi A, Barazane L, Manceur M, Essounbouli N \& Hamzaoui A, "Implementation of a new fuzzy vector control of induction motor", ISA Trans., Vol.53, No.3, (2014), pp.744-754.

[13] Hannan MA, Ali JA, Mohamed A \& Hussain A, "Optimization techniques to enhance the performance of induction motor drives: A review", Renew. Sustain. Energy Rev., (2017).

[14] Jiang Y, Xu W, \& Ye C, "Composite field-oriented control for linear induction motor based super-twisting sliding mode observers", IEEE Conference on Electromagnetic Field Computation (CEFC), (2016), pp. 1-1.

[15] Bucci G, Meo S, Ometto A, \& Scarano M, "The control of LIM by a generalization of standard vector techniques", Proceedings of IECON'94 20th Annual Conference of IEEE Industrial Electronics, Vol.1, (2002), pp.623-626.

[16] Mohamed EEM \& Sayed MA, "Matrix converters and three-phase inverters fed linear induction motor drives-Performance compare", Ain Shams Eng. J., (2016).

[17] Maktabdar O, Shamsinezhad M \& Eliasi H, "Effect of Reaction Plate on Performance of Single-Side Linear Induction Motor in Different Speeds and Frequencies with Finite Element Method", 9th Symposium on Advances in Science \& Technology (2015), pp.34-38.

[18] Liu A, Zhang H, Yang G \& Lin X, "Research and application of multi-objective particle swarm optimization in linear induction motor operating mechanism", 1st International Conference on Electric Power Equipment Switching Technology, (2011) pp.291295.

[19] Sang-Baeck Y, Jin H \& Dong-Seok H, "A method of optimal design of single-sided linear induction motor for transit", IEEE Trans. Magn., Vol.33, No.5, (1997), pp. 4215-4217.

[20] Kitamura M, Hino N, Nihei H \& Ito M, "A direct search shape optimization based on complex expressions of 2-dimensional magnetic fields and forces", IEEE Trans. Magn., Vol.34, No.5, (1998), pp.2845-2848.
[21] Laporte B, Takorabet N \& Vinsard G, "An approach to optimize winding design in linear induction motors", IEEE Trans. Magn., Vol.33, No.2, (1997), pp.1844-1847.

[22] Zare Bazghaleh A, Naghashan MR \& Meshkatoddini MR, "Optimum Design of Single-Sided Linear Induction Motors for Improved Motor Performance", IEEE Trans. Magn., Vol.46, No.11, (2010), pp.3939-3947.

[23] $\mathrm{Hu} \mathrm{D}, \mathrm{Xu} \mathrm{W}$, "Electromagnetic Design Optimization of SingleSided Linear Induction Motor for Improved Drive Performance Based on Linear Metro Application", Australasian Universities Power Engineering Conference, (2014).

[24] Ravanji MH \& Nasiri-Gheidari Z, "Design Optimization of a Ladder Secondary Single-Sided Linear Induction Motor for Improved Performance", IEEE Trans. Energy Convers., Vol.30, No.4, (2015), pp.1595-1603.

[25] Shiri A \& Shoulaie A, "End effect braking force reduction in highspeed single-sided linear induction machine", Energy Convers. Manag., Vol.61, (2012), pp. 43-50.

[26] Zayandehroodi H, Nasrabadian A \& Anoosheh R, "Cuckoo Optimization Algorithm Based Design For Low-Speed Linear Induction Motor", Özel Sayı Sci. J., Vol.36, No.6, (2015), pp.3037

[27] Ali JA, Hannan MA, Mohamed A \& Abdolrasol MGM, "Fuzzy logic speed controller optimization approach for induction motor drive using backtracking search algorithm", Measurement, Vol.78, (2016), pp.49-62.

[28] Ali JA, Hannan MA \& Mohamed A, "PSO algorithm for Three Phase Induction Motor drive with SVPWM Switching and V/f Control", IEEE International Conference on Power and Energy (PECon), (2014), pp.250-254.

[29] Abd Ali J, Hannan MA \& Mohamed A, "Improved indirect fieldoriented control of induction motor drive based PSO algorithm", J. Teknol., Vol.78, No.6-2, (2016).

[30] Abd Ali J, Hannan MA \& Mohamed A, "Gravitational search algorithm based tuning of a PI speed controller for an induction motor drive", IOP Conf. Ser. Earth Environ. Sci., Vol. 32, (2016).

[31] Chiang CL \& Su CT, "Tracking control of induction motor using fuzzy phase plane controller with improved genetic algorithm", Electr. Power Syst. Res., Vol.73, No.2, (2005), pp.239-247.

[32] Hannan MA, Ali JA, Mohamed A \& Hussain A, "Optimization techniques to enhance the performance of induction motor drives: A review", Renew. Sustain. Energy Rev., Vol.81, (2018), pp. 16111626.

[33] Mahapatra S, Daniel R, Dey DN \& Nayak SK, "Induction Motor Control Using PSO-ANFIS", Procedia Comput. Sci., Vol.48, (2015), pp. 753-768.

[34] Rojas CA, Rodriguez JR, Kouro S \& Villarroel F, "Multiobjective Fuzzy-Decision-Making Predictive Torque Control for an Induction Motor Drive", IEEE Trans. Power Electron., Vol.32, No.8, (2017), pp.6245-6260.

[35] Isfahani AH, Ebrahimi BM \& Lesani H, "Design Optimization of a Low-Speed Single-Sided Linear Induction Motor for Improved Efficiency and Power Factor", IEEE Trans. Magn., Vol.44, No.2, (2008), pp.266-272.

[36] Raja CVN \& Sudha KR, "Design, Analysis of Linear Induction Motor based on Harmony Search Algorithm and Finite Element Method", J. Eng. Sci. Technol. Rev., Vol.9, No.6, (2016), pp.189195

[37] Lucas C, Nasiri-Gheidari Z \& Tootoonchian F, “Application of an imperialist competitive algorithm to the design of a linear induction motor", Energy Convers. Manag., Vol.51, No.7, (2010), pp.14071411.

[38] Sijitha I \& Dr. Poorani S, "A Review on Design of Single Sided Linear Induction Motor to Improve Performance", International Journal of Pure and Applied Mathematics., Vol.116, No.22, (2017), pp.109-125. 